\title{
Sistema leptina-melanocortinas en la regulación de la ingesta y el peso corporal
}

José Luis Santos M.

\section{Leptin-melanocortin system, body weight regulation and obesity}

Obesity is a multifactorial disease that is rarely associated to single gene defects. However, due to their direct cause-effect relationships, those genetic defects that cause some forms of monogenic obesity are relevant in the study of mechanisms that contribute to increased energy intake and body fat accumulation. Most of the genes that have been shown to cause monogenic obesity are related to the leptin-melanocortin system. The functionality of this system has been elucidated through natural mutations (Agouti, ob and $\mathrm{db}$ ) in mice and knock-out models. Mutations related to human monogenic obesity have been described in leptin, leptin receptor, proopiomelanocortin, prohormone convertase 1 or melanocortin receptor 4 genes. Therapy with human recombinant leptin in patients with genetic deficiency of the hormone is an effective medical treatment of obesity, although only applicable to very few families. The use of leptin-melanocortin agonists, drugs to avoid leptin resistance or combinations of treatments with leptin and other satiating peptides are currently being investigated for multifacotiral human obesity (Rev Méd Chile 2009; 137: 1225-34).

(Key words: Leptin, Melanocortins; Obesity)

Recibido el 6 de marzo, 2009. Aceptado el 5 de agosto, 2009.

Trabajo financiado por FONDECYT \#1061096.

Departamento de Nutrición, Diabetes y Metabolismo, Facultad de Medicina, Pontificia Universidad Católica de Chile. Santiago de Chile.

aPhD Biología. MSc Bioestadística. MSc Epidemiología Genética.

$\mathrm{L}$ a obesidad común se caracteriza por un incremento excesivo de la grasa corporal en respuesta a un desequilibrio energético positivo mantenido en el tiempo. Aun considerando la

$\overline{\text { Correspondencia a: Prof. José Luis Santos. Departamento }}$ de Nutrición, Diabetes y Metabolismo, Edificio de Gastroenterología, Facultad de Medicina, Pontificia Universidad Católica de Chile. Alameda 340. Fono: 3543862 3543865. Fax: 6338298. E mail: jsantos@med.puc.cl decisiva influencia del ambiente obesogénico en la creciente epidemia de obesidad, existen también evidencias que apoyan la participación de factores genéticos en la determinación de rasgos como el índice de masa corporal (IMC) ${ }^{1}$. Contrariamente a lo que sucede con la obesidad de tipo multifactorial, la obesidad originada por el defecto de un solo gen es una condición rara $^{2}$. Sin embargo, debido a su relación directa causaefecto, los defectos genéticos causantes de obesidad monogénica son muy relevantes en el 
estudio de los factores que regulan la homeostasis energética.

La participación del sistema leptina-melanocortinas resulta esencial en la comprensión de los elementos que actúan sobre la regulación de la ingesta, por lo que presentaré en esta revisión las evidencias que apoyan el protagonismo de este sistema tanto en la obesidad de tipo monogénico como en la multifactorial.

Obesidad de tipo monogénico. Se han descrito mutaciones causantes de once formas de obesidad humana de tipo monogénico (Tabla 1$)^{3}$. Es importante subrayar que la mayoría de estos genes se relacionan primariamente con el control de la ingesta y especialmente con la regulación que ejerce la leptina en el sistema nervioso central a través del sistema de las melanocortinas.

Acción de la leptina en el núcleo arcuato hipotalámico. La leptina es una hormona secretada fundamentalmente en el tejido adiposo blanco y que circula en plasma en una concentración proporcional a la grasa corporal ${ }^{4}$. La leptina atraviesa la barrera hematoencefálica, e interactúa con su receptor específico en el núcleo arcuato del hipotálamo, actuando como una señal indicadora de las reservas energéticas. El núcleo arcuato presenta dos tipos de poblacio- nes neuronales con altos niveles de expresión del receptor de leptina: las neuronas POMC/ CART, que conducen señales anorexigénicas a través de los derivados de la proopiomelanocortina (POMC), y las neuronas AGRP/NPY, que conducen señales estimuladoras de la ingesta a través del neuropéptido Y (NPY) y la proteína relacionada con Agouti (AGRP). En situaciones de niveles reducidos o inexistentes de leptina (por ejemplo, en situaciones de ayuno prolongado o en la deficiencia genética de leptina), se favorece la expresión de AGRP/NPY, lo que impulsa a una mayor ingesta de alimentos. En situaciones de exceso de leptina, se promueve la expresión de POMC, que se escinde postraduccionalmente en péptidos llamados melanocortinas (entre ellas, $\alpha-\mathrm{MSH}$ y $\beta$-MSH; ver acrónimos en la Figura 1) que actuarían como ligandos endógenos del receptor 4 de melanocortina (MC4R). Por el contrario, AGRP actuaría como un agonista inverso en este receptor, promoviendo la ingesta de alimentos ${ }^{5,6}$.

Mutaciones en la leptina y su receptor. En 1994, se identificó el gen que codifica para la leptina y la mutación responsable de la obesidad masiva e hiperfagia que caracteriza a los ratones $\mathrm{Ob}^{7}$. La mutación consiste en una sustitución $\mathrm{C}>\mathrm{T}$ en la posición 105 en estado homocigoto que convier-

Tabla 1. Genes relacionados con la obesidad de tipo monogénico

$\begin{array}{ll}\text { Leptina } & \text { LEP (7q31.1; gene ID: 3952) } \\ \text { Receptor de leptina } & \text { LEPR (1p31; gene ID: 3953) } \\ \text { Receptor } 1 \text { de la hormona liberadora de corticotropina } & \text { CRHR1 (17q12-q22; gene ID: 1394) } \\ \text { Receptor } 2 \text { de la hormona liberadora de corticotropina } & \text { CRHR2 (7p14.3; gene ID: 1395) } \\ \text { Hormona concentradora de melanina } & \text { GPR24 (22q13.2; gene ID: 2847) } \\ \text { Prohormona convertasa 1 } & \text { PCSK1 (5q15-q21; gene ID: 5122) } \\ \text { Proopiomelanocortina } & \text { POMC ( 2p23.3; gene ID: 5443) } \\ \text { Receptor 3 de melanocortina } & \text { MC3R (20q13.2-q13.3; gene ID: 4159) } \\ \text { Receptor 4 de melanocortina } & \text { MC4R (18q22; gene ID: 4160) } \\ \text { Receptor del factor neurotrófico cerebral TrkB } & \text { NTRK2 (9q22.1; gene ID: 4915) } \\ \text { Homólogo } 1 \text { single-minded } & \text { SIM1 (6q16.3-q21; gene ID: 6492) }\end{array}$

Nomenclatura de genes: http://www.ncbi.nlm.nih.gov/gene/ 


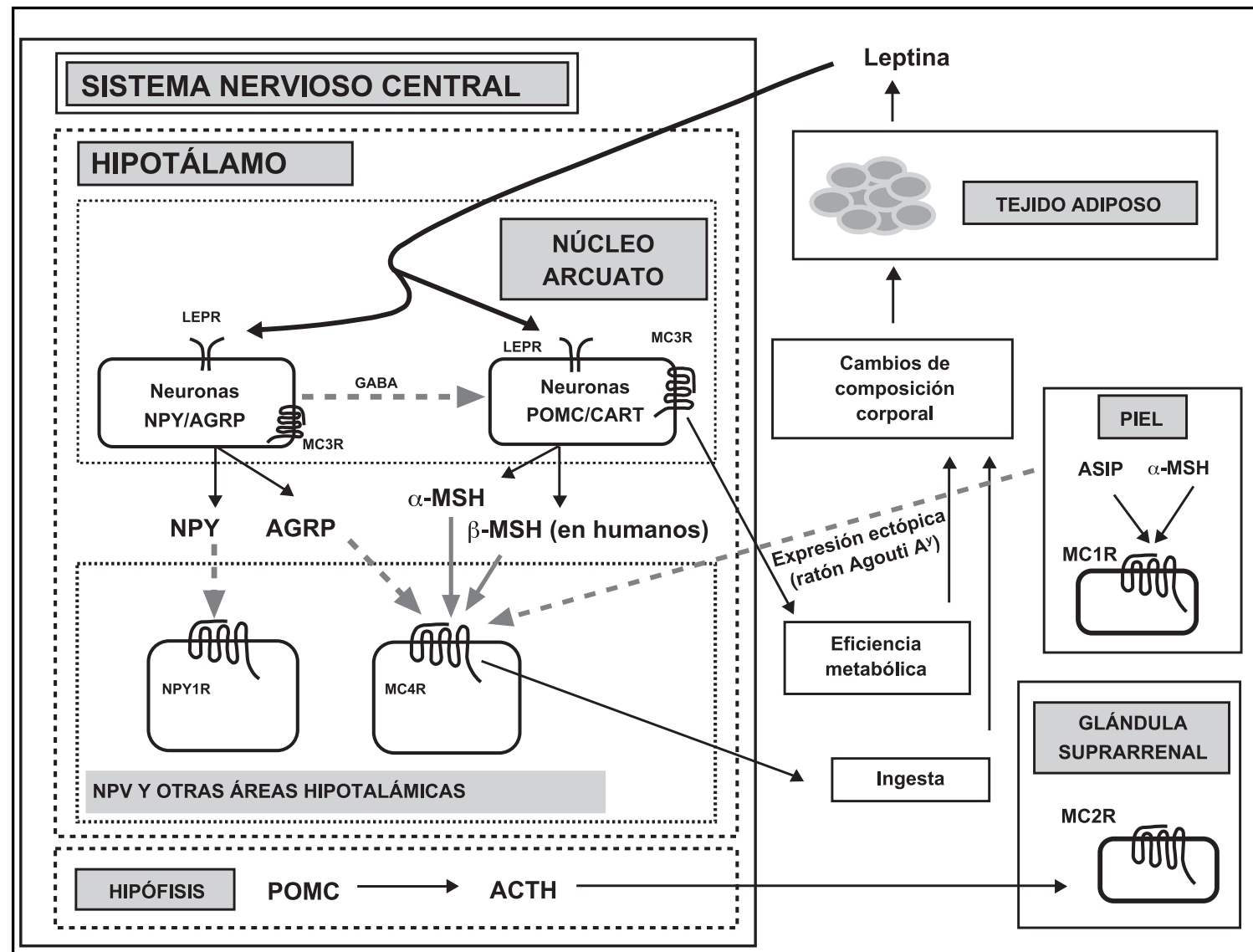

En gris línea continua: señales anorexigénicas. En gris línea discontinua: señales orexigénicas. POMC: proopiomelanocortina. CART: transcrito regulado por cocaína-anfetamina. AGRP: proteína relacionada con agouti. ASP: proteína señalizadora de agouti. NPY: neuropéptido Y. MSH: hormona ( $\alpha$ y b) estimulante de melanocitos. NPY1R: Receptor 1 de neuropéptido Y. MC1R-MC5R: receptores 1-5 de melanocortinas. ACTH: hormona adrenocorticotropa. LEP: leptina. LEPR: receptor de leptina. GABA: ácido $\gamma$-aminobutírico. NPV: núcleo paraventricular hipotalámico.

Figura 1. Regulación de la ingesta y composición corporal a través de la acción de la leptina sobre el sistema de las melanocortinas.

te un codón de arginina en un codón de terminación prematura ${ }^{8}$. De forma llamativa, la administración exógena de leptina disminuyó la excesiva ingesta del ratón ob y fue capaz de revertir su obesidad ${ }^{9,10}$. Otro modelo de ratón obeso es el ratón $\mathrm{db} / \mathrm{db}$, que presenta defectos genéticos en el receptor de leptina (sustitución
G>T en la posición 106). En estado homocigoto, esta mutación origina un fenotipo de obesidad similar al del ratón ob/ob, pero que no se revierte con la administración de leptina ${ }^{11}$. Las mutaciones causantes de obesidad monogénica humana que ocurren en el gen de la leptina (LEP) o en el receptor de la leptina (LEPR) son 
muy raras. Hasta el año 2009, se han descrito mutaciones del gen LEP en 5 familias de origen pakistaní (inserción de una $\mathrm{G}$ en la posición 133) y en una familia de origen turco (sustitución de arginina por triptófano en el codón 105) ${ }^{12,13}$. La administración exógena de leptina recombinante humana redujo sustancialmente el peso corporal y la ingesta en pacientes obesos homocigotos para estas mutaciones ${ }^{14}$. Adicionalmente, el estudio de dos pacientes deficientes en leptina evaluados antes y después de siete días de terapia de reemplazo, reveló que el comportamiento hiperfágico podría estar asociado a la activación de áreas cerebrales relacionadas con el placer y la recompensa ${ }^{15}$.

En el gen LEPR humano, se encontró una mutación en estado homocigoto (sustitución G>A en un sitio de corte-empalme) causante de obesidad e hiperfagia en una familia de Argelia con alto grado de consanguinidad ${ }^{16}$. Se han encontrado también otras mutaciones en LEPR que consisten en inserciones, cambios de aminoácidos o presencia de un codón prematuro de término, que podrían ser responsables de la obesidad de tipo monogénico presente hasta en 3\% de los sujetos obesos mórbidos ${ }^{17}$.

Principales vías de señalización de la leptina. El receptor de leptina es una proteína de membrana homóloga al receptor de la familia de las citoquinas clase 1. Existen diferentes isoformas del receptor generadas por un proceso de corte y empalme alternativo o procesamiento postraduccional $^{18}$. La unión de la leptina a la forma larga de su receptor en el hipotálamo promueve la dimerización del receptor de leptina, que activa a quinasas llamadas JAK2 que promueven su autofosforilación y la fosforilación de residuos de tirosina en LEPR. Esto conduce a la activación de factores de transcripción (STAT3), que se dimerizan y se translocan al núcleo promoviendo la expresión de péptidos anorexigénicos. En este sentido, tanto el ratón deficiente en STAT3 como el ratón mutado en el residuo Tyr1138 de LEPR, lugar clave para la interacción con STAT3, resultan en obesidad e hiperfagia ${ }^{19,20}$. La terminación de la señalización es inducida por otros factores (por ejemplo, SOCS3 y PTP1B), posiblemente a través de la acción de JAK2. De forma interesante, la haploinsuficiencia o deficiencia genética de factores de terminación de la señal de leptina generan ratones con hipersensibilización a la leptina y resistencia a la obesidad inducida por $\operatorname{dieta}^{21}$.

Otra ruta de señalización activada por la leptina es la fosfatidil inositol 3 quinasa $(\mathrm{PI} 3 \mathrm{~K})^{22}$, en la que se induce la fosforilación de residuos de tirosina en el sustrato del receptor insulínico 2 (IRS2) mediante JAK2, que a su vez fosforilan y activan PI3K. Un ejemplo de la importancia de esta ruta es la anulación genética de IRS2 en el ratón, que conduce a obesidad e hiperfagia ${ }^{23}$. Adicionalmente, $\mathrm{SH} 2 \mathrm{~B}$ es una proteína citosólica que simultáneamente se une a JAK2 e IRS2, promoviendo la activación de la ruta $\mathrm{PI} 3 \mathrm{~K}^{24}$. El ratón deficiente en este gen desarrolla resistencia a la insulina y a la leptina, así como hiperfagia y obesidad ${ }^{25}$. La ruta PI3K es también activada por la unión de la insulina a su receptor, lo que supone un punto de confluencia entre la señalización de estas dos hormonas relacionadas estrechamente con la homeostasis energética ${ }^{26}$.

Mutaciones en los receptores 3 y 4 de melanocortina. El sistema de las melanocortinas está compuesto por: a) la proopiomelanocortina (POMC) y los péptidos derivados de POMC que actúan como ligandos de los receptores de melanocortinas: $\alpha-\beta-$ y $\gamma$-MSH (Hormonas $\alpha, \beta-$ y $\gamma$ estimulantes de melanocitos), así como la hormona adrenocorticotropa (ACTH). b) una familia de cinco receptores de melanocortina (MC1R-MC5R); y c) los péptidos que antagonizan el efecto de los ligandos derivados de POMC: AGRP (proteína relacionada con agouti) y ASIP (proteína señalizadora de agouti) ${ }^{27}$.

Los receptores de melanocortinas pertenecen a una familia de 5 miembros (MC1R - MC5R) de receptores acoplados a proteína G. Entre ellos, MC3R y MC4R se expresan en regiones del sistema nervioso central directamente relacionadas con el control del apetito. El ratón con deficiencia genética de MC4R muestra signos evidentes de obesidad, hiperfagia y crecimiento lineal acelerado ${ }^{28}$. En humanos, las mutaciones en MC4R juegan un papel importante dado que se han descrito más de 100 diferentes mutaciones que constituyen la causa más frecuente de obesidad de tipo monogénico $(0,5 \%-6 \%$ de los pacientes con obesidad 
mórbida $)^{29,30}$. El efecto de las mutaciones de MC4R sobre el índice de masa corporal (IMC) se ha estudiado en hermanos de portadores de mutaciones en MC4R, determinándose diferencias entre 4 y $9,5 \mathrm{~kg} / \mathrm{m}^{2}$ al comparar portadores de mutaciones versus no-portadores ${ }^{31}$.

El ratón deficiente de MC3R se caracteriza por un aumento modesto de la masa grasa, así como una mayor eficiencia metabólica, sin signos de hiperfagia ${ }^{32}$. Se ha propuesto que MC3R actuaría como un autorreceptor inhibitorio expresado en neuronas POMC/CART, pero también expresado en neuronas AGRP/NPY, lo que posiblemente se relacionaría con la regulación de los impulsos inhibitorios que ejercen estas neuronas sobre POMC/CART a través del ácido $\gamma$-aminobutírico (GABA) (Figura 1) 21,33. En humanos, la importancia de las mutaciones en MC3R se ha sugerido en dos casos de obesidad mórbida debidas a la mutación Ile183Asn, así como en otras mutaciones raras que afectan a la funcionalidad de este receptor ${ }^{34}$.

Mutaciones que afectan al gen de proopiomelanocortina y su procesamiento. El ratón deficiente en POMC se caracteriza por presentar hiperfagia y obesidad, pigmentación alterada, hiperleptinemia, y ausencia de hormona adrenocorticotropa ${ }^{35}$. En humanos, la importancia de POMC se ha manifestado a través de mutaciones raras en su secuencia codificante que producen un fenotipo de obesidad severa e hiperfagia, pelo rojo y piel pálida (por alteración de la pigmentación a través de MC1R que se expresado en la piel) y a una deficiencia de ACTH (por defectos de la esteroidogénesis derivados de la falta de acción de ACTH sobre MC2R en la glándula suprarrenal) ${ }^{36,37}$. En aproximadamente $1 \%$ de los sujetos obesos, se ha descrito la mutación Try221Cys en la región de POMC codificante para $\mathrm{B}-\mathrm{MSH}$ que produce un fenotipo de hiperfagia, lo que subraya la posible relevancia de $\mathrm{B}-\mathrm{MSH}$ en el comportamiento humano de alimentación ${ }^{38}$.

Las prohormonas convertasas 1 y 2 (PCSK1 y PCSK2) son enzimas que actúan escindiendo POMC en un proceso postraduccional que es diferente en el hipotálamo con respecto a la hipófisis ${ }^{39}$. La deficiencia genética de PCSK1 se ha descrito en dos casos de obesidad con mutaciones en estado de heterocigoto compuesto ${ }^{40}$. Por el contrario, el ratón deficiente en esta enzima no presenta un claro fenotipo de obesidad, caracterizándose por un tamaño corporal reducido y múltiples defectos endocrinos, tales como niveles indetectables de insulina y altos niveles de proinsulina, dado que PCSK1 es la responsable del procesamiento de diferentes prohormonas y neuropéptidos ${ }^{41}$. En este sentido, la obesidad humana por deficiencia de PCSK1 parece tener mayores similitudes con el modelo de ratón obeso fat/fat generado por la ausencia de carboxipeptidasa $\mathrm{E}$ que con la deficiencia genética de Pcsk1 en el ratón ${ }^{42}$.

Obesidad genética en el ratón agouti obeso. El ratón obeso amarillo es producido por la mutación dominante $\mathrm{A}^{\mathrm{y}}$, que se caracteriza por una deleción que fusiona un gen de expresión ubicua con el gen Agouti o ASIP ("proteína señalizadora de agouti" ${ }^{43}$. En condiciones normales, ASIP se expresa sólo de forma transitoria en el pelo y actúa sobre MC1R para generar phaeomelanina en lugar de eumelanina, lo que resulta en un pelaje de color amarillo irisado o color agouti ${ }^{44}$ (Figura 1). En estado heterocigoto, $A^{y}$ produce una expresión ubicua de ASIP, lo que provocaría su acción en el sistema nervioso central, simulando el efecto de AGRP. Esta mutación genera por un lado un fenotipo caracterizado por hiperfagia y obesidad por estimulación de MC4R, y por otro lado un pelaje de color amarillo que se explicaría por una sobreestimulación de MC1R en la piel. Existe otra mutación que se conoce como $\mathrm{A}^{\mathrm{vy}}$, que se caracteriza por producir un patrón variable de inactivación epigenética de ASIP en función del grado de metilación de las regiones reguladoras de este gen, lo que se traduce en ratones con un grado variable de sobrepeso y pigmentación amarilla de la piel ${ }^{45}$.

El péptido AGRP es un ligando endógeno de MC4R que actúa promoviendo la ingesta de alimentos. AGRP fue identificado por alta identidad con ASIP, pero con una expresión exclusiva en el sistema nervioso central y en la glándula suprarrenal ${ }^{46}$. AGRP presenta una sobreexpresión hipotalámica en estados de ayuno, y una expresión 5-10 veces superior en el ratón ob/ob comparado con el ratón normal, que retorna a valores normales tras la administración de leptina exógena. Inicialmente, el ratón knock-out para 
AGRP (y NPY) no mostró fenotipo de hipofagia o delgadez hasta la vejez. Sin embargo, estudios posteriores han demostrado que la destrucción selectiva de neuronas AGRP/NPY por expresión del receptor de la toxina diftérica, genera un ratón delgado e hipofágico ${ }^{47}$.

Interacción del sistema leptina-melanocortinas con otros sistemas reguladores de la ingesta. Se ha observado que la anulación selectiva del receptor de leptina exclusivamente en neuronas POMC/CART produce una obesidad de menor magnitud que la descrita en el ratón $\mathrm{db} / \mathrm{db}$, lo que subraya la importancia de la leptina y su receptor más allá de su acción a través del núcleo arcuato ${ }^{48,49}$. Centrándonos en el sistema leptina-melanocortinas, los axones de las neuronas POMC/CART y AGRP/NPY alcanzan a proyectarse a otras regiones hipotalámicas importantes en la regulación de la ingesta tales como el núcleo paraventricular, el área hipotalámica lateral, el núcleo ventromedial y el núcleo dorsomedial, que expresan $\mathrm{MC} \mathrm{R}^{5}$. Por otro lado, también se ha descrito la expresión de MC4R en el núcleo del tracto solitario, donde actuaría sobre el efecto de saciedad inducido por factores generados en el intestino ${ }^{50}$. Adicionalmente, se ha descrito que la serotonina, un neurotransmisor relacionado con la supresión de la ingesta, podría modular también la liberación de agonistas y antagonistas de MC4R ${ }^{51}$. Recientemente, se ha propuesto que antagonistas sintéticos de MC4R podrán bloquear el efecto de saciedad inducido por el neurotransmisor nesfatina ${ }^{52}$.

La unión de ligandos de melanocortinas a MC4R provoca una inhibición de la ingesta mediante mecanismos que parecen incluir al factor neurotrófico cerebral BDNF ${ }^{53}$. Esta neurotrofina promueve la proliferación, regeneración, plasticidad y conectividad neuronal durante el desarrollo madurativo. En ratones, la deleción selectiva del gen homólogo al BDNF humano en núcleos hipotalámicos genera un comportamiento hiperfágico que conduce a la obesidad ${ }^{54}$. En humanos, el importante papel de las neurotrofinas se ha manifestado en un caso de obesidad severa con hiperactividad y deficiencia cognitiva, caracterizado por una haploinsuficiencia de $\mathrm{BDNF}^{55}$, así como por la obesidad e hiperfagia por la pérdida de un segmento cromosómico que contiene al gen BDNF en algunos pacientes afectados con el síndrome WAGR ${ }^{56}$ (OMIM \#194072). También se ha descrito un caso de obesidad caracterizado por hiperfagia y retraso mental, con una mutación en estado heterocigoto (Tyr722Cys) en el gen NTRK2, que codifica para el receptor de $\mathrm{BDNF}^{57}$.

El sistema leptina-melanocortina en la obesidad de tipo multifactorial. En seres humanos, la condición habitual en la obesidad no es la deficiencia de leptina, sino el exceso de leptina plasmática $^{58}$. La leptina circulante se encuentra libre o unida a su receptor soluble, que resulta de la ruptura proteolítica de receptores unidos a membrana, existiendo diferencias en el cociente de leptina libre/unida dependiendo del estado nutricional ${ }^{59}$. Se han descrito variaciones plasmáticas de leptina determinadas principalmente por la cantidad de grasa corporal, el sexo (mayor en mujeres que en hombres), ritmos circadianos y presencia de ayuno prolongado ${ }^{58-61}$, lo que es concordante con un efecto de resistencia a la acción de la leptina como factor contribuyente al desarrollo de obesidad común. Una posible explicación a la resistencia a la leptina propia de la obesidad multifactorial podría basarse en deficiencias en la señal intracelular o en un deficiente transporte de la leptina a través de la barrera hematoencefálica, que pudiera estar facilitado por las formas cortas de su receptor ${ }^{62}$. En apoyo de esta hipótesis, se ha descrito que la razón de concentración de leptina en plasma en relación a su concentración en el líquido cefalorraquídeo, es diferente en sujetos obesos versus sujetos normopeso ${ }^{63}$.

En los últimos años, el acercamiento de estudios de asociación de genoma completo está permitiendo la determinación de hasta 1 millón de variantes genéticas en un solo ensayo (ver paneles de variación genética en www.illumina.com o www.affymetrix.com), lo que ha supuesto una revolución en el área de la epidemiología genéti$\mathrm{ca}^{64}$. Este enfoque ha permitido identificar diferentes genes de susceptibilidad frente a la obesidad como el gen FTO, cuya elevada expresión hipotalámica indica una posible relación con la ingesta. Adicionalmente, también se han asociado con obesidad a los polimorfismos simples del 
gen SH2B1, que participa en la señalización de la leptina, una variante común próxima a MC4R o polimorfismos del gen $\mathrm{BDNF}^{65-67}$. Una nueva visión de la participación de MC4R en la obesidad se refiere a la reciente observación de autoanticuerpos frente a MC4R en una significativa proporción de sujetos obesos ${ }^{68}$, lo que abre expectativas sobre el papel de la autoinmunidad frente a factores involucrados en la homeostasis energética.

Sistema leptina-melanocortinas y tratamiento de la obesidad. La terapia hormonal con leptina recombinante humana aplicada en pacientes con deficiencia genética de leptina constituye el único ejemplo, aunque sólo aplicable a unas pocas familias, de tratamiento efectivo frente a la obesidad ${ }^{14}$. Sin embargo, los ensayos clínicos aleatorizados con diferentes dosis de leptina en pacientes con obesidad común, no han producido el efecto esperado en términos de disminución de la ingesta o reducción del peso corporal ${ }^{69}$. Sin embargo, la administración simultánea de leptina junto con un análogo de la amilina (péptido pancreático de efecto saciante), podría tener mayor in-

\section{REFERENCIAS}

1. Clement K, Sorensen TiA. Obesity: genomics and postgenomics. Informa Healthcare. New York 2007.

2. Farooqi IS, O'Rahilly S. Monogenic obesity in humans. Annu Rev Med 2005; 56: 443-58.

3. Rankinen T, Zuberi A, Chagnon YC, Weisnagel SJ, Argyropoulos G, Walts B, et al. The human obesity gene map: the 2005 update. Obesity 2006; 14: 529644.

4. Faroodi IS, O’Rahilly S. Leptin: a pivotal regulator of human energy homeostasis. Am J Clin Nutr 2009 (Suppl); 89: 980S-984S.

5. Cone RD. Anatomy and regulation of the central melanocortin system. Nat Neurosci 2005; 8: 571-8.

6. Seeley RJ, Drazen DL, Clegg DJ. The critical role of the melanocortin system in the control of energy intake. Annu Rev Nutr 2004; 24: 133-49.

7. Ingalls AM, Dickie MD, Snell GD. Obese, new mutation in the mouse. J Hered 1950; 41: 317-8. fluencia en la pérdida de peso corporal ${ }^{70}$. Una posible causa de la resistencia a la leptina en la obesidad multifactorial podría relacionarse con una deficiente señalización intracelular. En este sentido, se ha realizado un ensayo terapéutico con el uso del Factor Neurotrófico Ciliar (CTNF) como agente reductor del peso y de la ingesta ${ }^{71}$, dado que CTNF comparte con la leptina bastantes similitudes en la señalización celular y pudiera evitar el efecto de la resistencia a la leptina. En un enfoque alternativo, se ha descrito la eficacia de drogas que actúan sobre el estrés del retículo endoplásmico en ratones, como una forma de reducir la resistencia a la leptina ${ }^{72}$.

Se ha descrito que las intervenciones conducentes a la pérdida de peso basadas en la modificación del estilo de vida en niños obesos son igualmente efectivas en no-portadores versus portadores de mutaciones en MC4R, aunque estos últimos presentaron una mayor dificultad en el mantenimiento del peso ${ }^{73}$. Dada la importancia del sistema leptina-melanocortinas, es probable que surjan nuevas terapias antiobesidad basadas en el uso de agonistas de receptores en este sistema $^{29}$. 
13. Strobel A, Issad T, Camoin L, Ozata M, Strosberg AD. A leptin missense mutation associated with hypogonadism and morbid obesity. Nat Genet 1998; 18 : 213-5.

14. Faroodi IS, Jebb Sa, Langmack G, Lawrence E, Cheetham CH, Prentice AM et al. Effects of recombinant leptin therapy in a child with congenital leptin deficiency. N Engl J Med 1999; 341: 879-84.

15. Faroogi Is, Bullmore E, Keogh J, Gillard J, O'Rahielly S, FLETCHER PC ET AL. Leptin regulates striatal regions and human eating behavior. Science 2007; 317: 1355.

16. Clément K, Vaisse C, lahlou N, Cabrol S, Pelloux V, Cassuto D et al. A mutation in the human leptin receptor gene causes obesity and pituitary dysfunction. Nature 1998; 392: 398-401.

17. Faroodi IS, Wangensteen T, Collins S, Kimber W, Matarese G, Keogh JM et al. Clinical and molecular genetic spectrum of congenital deficiency of the leptin receptor. N Engl J Med 2007; 356: 237-47.

18. Lee GH, Proenca R, Montez JM, Carroll KM, DarvishZADEH JG, LeE JI ET AL. Abnormal splicing of the leptin receptor in diabetic mice. Nature 1996; 379: 632-5.

19. Bates SH, Stearns WH, Dundon TA, Schubert M, Tso AW, WANG Y ET AL. STAT3 signalling is required for leptin regulation of energy balance but not reproduction. Nature 2003; 421: 856-9.

20. Gao Q, Wolfgang MJ, Neschen S, Morino K, Horvath TL, Shulman GI et al. Disruption of neural signal transducer and activator of transcription 3 causes obesity, diabetes, infertility, and thermal dysregulation. Proc Natl Acad Sci USA 2004; 101: 4661-6.

21. Oswal A, Yeo GSH. The leptin melanocortin pathway and the control of body weight: lessons from human and murine genetics. Obes Rev 2007; 8: 293-306.

22. Niswender KD, Morton GJ, Stearns Wh, Rhodes CJ, Myers MG JR, SCHWARTZ MW ET AL. Intracellular signalling. Key enzyme in leptin-induced anorexia. Nature 2001; 413: 794-5.

23. Withers DJ, Gutierrez JS, Towery H, Burks DJ, Ren JM, PREvis S ET AL. Disruption of IRS-2 causes type 2 diabetes in mice. Nature 1998; 391: 900-4.

24. Duan C, Li M, Rui L. SH2-B promotes insulin receptor substrate (IRS)1- and IRS2-mediated activation of the phosphatidylinositol 3-kinase pathway in response to leptin. J Biol Chem 2004; 279: 43684-91.

25. Ren D, Li M, Duan C, Rui L. Identification of SH2-B as a key regulator of leptin sensitivity, energy balance, and body weight in mice. Cell Metab 2005; 2: $95-104$

26. Xu AW, Kaelin CB, Takeda K, Akira S, Schwartz MW, BARSH GS ET AL. PI3K integrates the action of insulin and leptin on hypothalamic neurons. J Clin Invest 2005; 115: 951-8.
27. Gantz I, Fong TM. The melanocortin system. Am J Physiol Endocrinol Metab 2003; 284: E468-E474.

28. Huszar D, Lynch CA, Fairchild-Huntress V, Dunmore JH, Fang Q, Berkemeier LR et al. Targeted disruption of the melanocortin- 4 receptor results in obesity in mice. Cell 1997; 88: 131-41.

29. Faroodi IS, O’Rahilly S. Mutations in ligands and receptor of the leptin-melanocortin pathway that lead to obesity. Nat Clin Pract 2008; 4: 569-77.

30. Santos Jl, Amador P, Valladares M, Albala C, Martinez JA, MARTI A. Obesity and eating behaviour in a threegeneration Chilean family with carriers of the Thr150Ile mutation in the melanocortin- 4 receptor gene. J Physiol Biochem 2008; 64: 205-10.

31. Dempfle A, Hinney A, Heinzel-Gutenbrunner M, RaAb M, Geller F, Gudermann T Et al. Large quantitative effect of melanocortin- 4 receptor gene mutations on body mass index. J Med Genet 2004; 41: 795-800.

32. Chen as, Marsh DJ, Trumbauer me, Frazier EG, Guan $\mathrm{XM}, \mathrm{Yu} \mathrm{H}$ ET AL. Inactivation of the mouse melanocortin-3 receptor results in increased fat mass and reduced lean body mass. Nat Genet 2000; 26: 97-102.

33. Butler A. The melanocortin system and energy balance. Peptides 2006; 27: 281-90.

34. Mencarelli M, Walker GE, Maestrini S, Alberti L, Verti B, Brunani A et al. Sporadic mutations in melanocortin receptor 3 in morbid obese individuals. Eur J Hum Genet 2008; 16: 581-6.

35. Yaswen L, Diehl N, Brennan MB, Hochgeschwender U. Obesity in the mouse model of pro-opiomelanocortin deficiency responds to peripheral melanocortin. Nat Med 1999; 5: 1066-70.

36. Coll aP, Faroogi Is, Challis BG, Yeo GS, O’Rahilly S. Proopiomelanocortin and energy balance: insights from human and murine genetics. J Clin Endocrinol Metab 2004; 89: 2557-62.

37. Krude H, Biebermann H, Schnabel D, Tansek MZ, Theunissen P, Muldis PE et al. Obesity due to proopiomelanocortin deficiency: three new cases and treatment trials with thyroid hormone and ACTH4-10. J Clin Endocrinol Metab 2003; 88 : 4633-40.

38. Lee Ys, Challis BG, Thompson DA, Yeo GS, Keogh JM, Madonna ME et Al. A POMC variant implicates beta-melanocyte-stimulating hormone in the control of human energy balance. Cell Metab 2006; 3 : $135-40$.

39. Millington GWM. The role of proopiomelanocortin (POMC) neurones in feeding behaviour. Nutr Metab 2007; 4: 18.

40. Jackson RS, Creemers JW, Faroodi IS, RafFin-Sanson ML, Varro A, Dockray GJ ET Al. Small-intestinal dysfunction accompanies the complex endocrinopathy of human proprotein convertase 1 deficiency. J Clin Invest 2003; 112: 1550-60. 
41. Zhu X, Zhou A, Dey A, Norrbom C, Carroll R, Zhang C ET AL. Disruption of PC1/3 expression in mice causes dwarfism and multiple neuroendocrine peptide processing defects. Proc Natl Acad Sci USA 2002; 99: 10293-8

42. Naggert JK, Fricker LD, Varlamov O, Nishina PM, Rouille Y, Steiner DF et al. Hyperproinsulinaemia in obese fat/fat mice associated with a carboxypeptidase E mutation which reduces enzyme activity. Nat Genet 1995; 10: 135-42.

43. Barsh G. From Agouti to Pomc-100 years of fat blonde mice. Nat Med 1999; 5: 984-5.

44. Miltenberger RJ, Mynatt RL, Wilkinson E, Woychik R. The Role of the agouti Gene in the Yellow Obese Syndrome. J Nutr 1997; 127: 1902S-1907S.

45. Jirtle RL, Skinner MK. Environmental epigenomics and disease susceptibility. Nat Rev Genet 2007; 8: 253-62.

46. Stutz A, Morrison C, Argyropoulos G. The Agoutirelated protein and its role in energy homeostasis. Peptides 2005; 26: 1771-81.

47. Luquet S, Pérez FA, Hnasko TS, Palmiter RD. NPY/ AGRP neurons are essential for feeding in adult mice but can be ablated in neonates. Science 2005; 310: 683-5.

48. Cowley MA, Smart Jl, Rubinstein M, Cerdán MG, Diano S, Horvath TL ET AL. Leptin activates anorexigenic POMC neurons through a neural network in the arcuate nucleus. Nature 2001; 411: 480-4.

49. Balthasar N, Coppari R, Mcminn J, Liu SM, Lee CE, Tang $\mathrm{V}$ ET AL. Leptin receptor signalling in POMC neurons is required for normal body weight homeostasis. Neuron 2004; 42: 983-91.

50. Sutton GM, Duos B, Patterson LM, Berthoud Hr. Melanocortinergic modulation of cholecystokinininduced suppression of feeding through extracellular signal-regulated kinase signaling in rat solitary nucleus. Endocrinology 2005; 146: 3739-47.

51. Heisler LK, Jobst Ee, Sutton GM, Zhou L, Borok E, Thornton-Jones Z ET AL. Serotonin reciprocally regulates melanocortin neurons to modulate food intake. Neuron 2006; 51: 239-49.

52. Myers MG. Keeping the fat off with nesfatin. Nat Med 2006; 12: 1248-9.

53. Xu B, Goulding EH, Zang K, Cepoi D, Cone RD, Jones KR ET AL. Brain-derived neurotrophic factor regulates energy balance downstream of melanocortin-4 receptor. Nat Neurosci 2003; 6: 736-42.

54. Unger TJ, Calderon GA, Bradley lC, Sena-Esteves M, Rios M. Selective deletion of Bdnf in the ventromedial and dorsomedial hypothalamus of adult mice results in hyperphagic behavior and obesity. J Neurosci 2007; 27: 14265-74.

55. Gray J, Yeo GS, Cox JJ, Morton J, Adlam AL, Keogh JM ET AL. Hyperphagia, severe obesity, impaired cognitive function, and hyperactivity associated with functional loss of one copy of the brain-derived neurotrophic factor (BDNF) gene. Diabetes 2006; 55 : 3366-71.

56. Han JC, Liu QR, Jones M, Levinn RL, Menzie CM, JeFFERSON-GEORGE KS ET AL. Brain-derived neurotrophic factor in the WAGR syndrome. N Engl J Med 2008; 359: 918-27.

57. Yeo GS, Connie Hung CC, Rochford J, Keogh J, Gray J, Sivaramakrishnan $S$ et al. A de novo mutation affecting human TrkB associated with severe obesity and developmental delay. Nat Neurosci 2004; 7: 1187-9.

58. Considine RV, Sinha MK, Heiman ML, Kriauciunas A, Stephens TW, Nyce MR et al. Serum immunoreactiveleptin concentrations in normal-weight and obese humans. N Engl J Med 1996; 334: 292-5.

59. Maamra M, Bidlingmaier M, Postel-Vinay MC, Wu Z, Strasburger CJ, Ross RJ et al. Generation of human soluble leptin receptor by proteolytic cleavage of membrane-anchored receptors. Endocrinology 2001; 142: 4389-93.

60. Sinha MK, Sturis J, Ohannesian J, Magosin S, Stephens T, Heiman ML et al. Ultradian oscillations of leptin secretion in humans. Biochem Biophys Res Commun 1996; 228: 733-8.

61. Boden G, Chen X, Mozzoli M, Ryan I. Effect of fasting on serum leptin in normal human subjects. J Clin Endocrinol Metab 1996; 81: 3419-23.

62. Hileman SM, Pierroz DD, Masuzaki H, Bjørbaek C, El-Haschimi K, Banks WA H et al. Characterization of short isoforms of the leptin receptor in rat cerebral microvessels and of brain uptake of leptin in mouse models of obesity. Endocrinology 2002; 143: 775-83.

63. Caro JF, Kolaczynski JW, Nyce MR, Ohannesian JP, Opentanova I, Goldman WH et al. Decreased cerebrospinal-fluid/serum leptin ratio in obesity: a possible mechanism for leptin resistance. Lancet 1996; 348: 159-61.

64. The Wellcome Trust Case Control Consortium. Genome-wide association study of 14,000 cases of seven common diseases and 3,000 shared controls. Nature 2007: 447: 661-78.

65. Willer CJ, Speliotes EK, Loos RJ, Li S, Lindgren CM, Heid IM et AL. Six new loci associated with body mass index highlight a neuronal influence on body weight regulation. Nat Genet 2009; 41: 25-34.

66. Thorleifsson G, Walters GB, Gudbjartsson DF, Steinthorsdottir V, Sulem P, Helgadottir A et al. Genomewide association yields new sequence variants at seven loci that associate with measures of obesity. Nat Genet 2009; 41: 18-24.

67. Loos RJ, Lindgren CM, Li S, Wheeler E, Zhao JH, 
PROKOPENKO I ET AL. Common variants near MC4R are associated with fat mass, weight and risk of obesity. Nat Genet 2008; 40: 768-75.

68. Peter JC, Bekel A, Lecourt AC, Zipfel G, Eftekhari P, Nesslinger M ET AL. Anti-melanocortin-4 receptor autoantibodies in obesity. J Clin Endocrinol Metab 2009; 94: 793-800.

69. Heymsfield SB, Greenberg as, Fujioka K, Dixon RM, Kushner R, Hunt TK et al. Recombinant leptin for weight loss in obese and lean adults: a randomized, controlled, dose-escalation trial. JAMA 1999; 282: 1568-75.

70. Ravussin E, Smith SR, Mitchell JA, Shringarpure R, Shan K, Maier H et AL. Enhanced weight loss with pramlintide/metreleptin: an integrated neurohormo- nal approach to obesity pharmacotherapy. Obesity 2009 [Epub ahead of print].

71. Ettinger MP, Littlejohn TW, Schwartz SL, Weiss SR, Mcilwain HH, Heymsfield SB et al. Recombinant variant of ciliary neurotrophic factor for weight loss in obese adults: a randomized, dose-ranging study. JAMA 2003; 289: 1826-32.

72. Ozcan L, Ergin AS, Lu A, Chung J, Sarkar S, Nie D et AL. Endoplasmic Reticulum Stress Plays a Central Role in Development of Leptin Resistance. Cell Metabolism 2009; 9: 35-51.

73. Reinehr T, Hebebrand J, Friedel S, Toschie AM, Brumm H, Biebermann H, Hinney A. Lifestyle intervention in obese children with variations in the melanocortin 4 receptor gene. Obesity 2009; 17: 382-9. 